\title{
ACTIVE POWER AND FREQUENCY ANALYSIS OF A SMART GRID - USING MATLAB/SIMULINK APPROACH
}

\author{
Vikash Kumar ${ }^{1}$, Pankaj Rai ${ }^{2}$ \\ ${ }^{1}$ Asstt. Professor, EEE Department, BACET, Jamshedpur \\ ${ }^{2}$ Department of Electrical Engg, BIT Sindri, Dhanbad
}

\begin{abstract}
In this paper, a Smart Grid has been designed by MATLAB/SIMULINK approach for synchronization of Thermal and Wind power plant and for analysis of Active power and grid frequency. Analysis of Active power and frequency gives the exact idea to know the range of maximum permissible loads that can be connected to their relevant bus bars. The Smart Grid, regarded as the next generation power grid, uses two-way flow of electricity and information to create a widely distributed automated energy delivery network
\end{abstract}

Keywords: SIMULINK, Smart Grid, Frequency Deviation, Active power, Load Analysis

\section{INTRODUCTION}

A future Smart Grid power system network is a dynamic network for bi-directional energy flows, linking widely distributed small capacity renewable energy systems at consumer level (distribution network) and centralized higher-capacity power generators, facilitating active participation of customer choice for energy production/source and demand management, and providing real-time information on the performance and optimal operation of the power system network [1]. Smart grid is technically classified in three categories namely Smart Infrastructure System, Smart Management System and Smart Protection System [2].The simulation works of this paper is done under the Smart Power generation [3] technique which is a part of Smart Infrastructure System.

Frequency and Active power are the main parameters to show the stability of any power system network like conventional power grid, microgrid or any virtual power plant [4].The analysis of frequency control has already done in Isolated Microgrids [5]. Micro grid is designed to operate in grid connected and isolated mode [6]. To control the frequency in isolated micro grid, storage element is necessary [7].Different rating of storage and integrating devices are used to control the frequency can creates very complex situation [8]. Active and Reactive Power Control of the Electronically Interfaced DG Sources for the Realization of a Virtual Power Plants also been done [9].This research paper only depicts the power flow analysis in virtual power plant having small capacity.

In present scenario of power system network, conventional and distributed generation are combinedly used to control the active power flow in order to get a highly stable network. This paper is about to synchronize these two power plant namely thermal and wind power plant because both sharing maximum percentage of electricity generation in their respective field. The smart grid model includes 4 units of Thermal power plant (conventional generation) and 6 units of Wind power plant (distributed generation). Wind power plant is connected to major load side to control the power flow and this connecting point is treated as smart grid. Power generated in Thermal power plant is done by Synchronous generated and in Wind power plant Doubly Feded induction generator (DFIG) [10].The rating of each thermal power plant is $900 \mathrm{MW}$ where as wind power plant rating is $12 \mathrm{MW}$. $13.8 \mathrm{KV}$ is generated by synchronous generated which is then step-up to $230 \mathrm{KV}$ of voltage level and $575 \mathrm{~V}$ is generated by DFIG which is again step-up to $230 \mathrm{KV}$ because transmission voltage is $230 \mathrm{KV}$. The model simulates the power system network with two area system control where each area is characterised with two conventional thermal power plant each having $900 \mathrm{MW}$ capacity.

\section{ACTIVE POWER AND FREQUENCY ANALYSIS AND CONTROLMETHOD}

Active power and frequency analysis process and control of this power system is explained by two ways and they are as:

(i) By Automatic load frequency control (ALFC) loop of synchronous generator and measuring active power values at each individual bus bar.

(ii) By Automatic frequency control of doubly fed induction generator and measuring active power values at each individual bus bar. 


\subsection{Frequency and Active Power Control of} Synchronous Generator

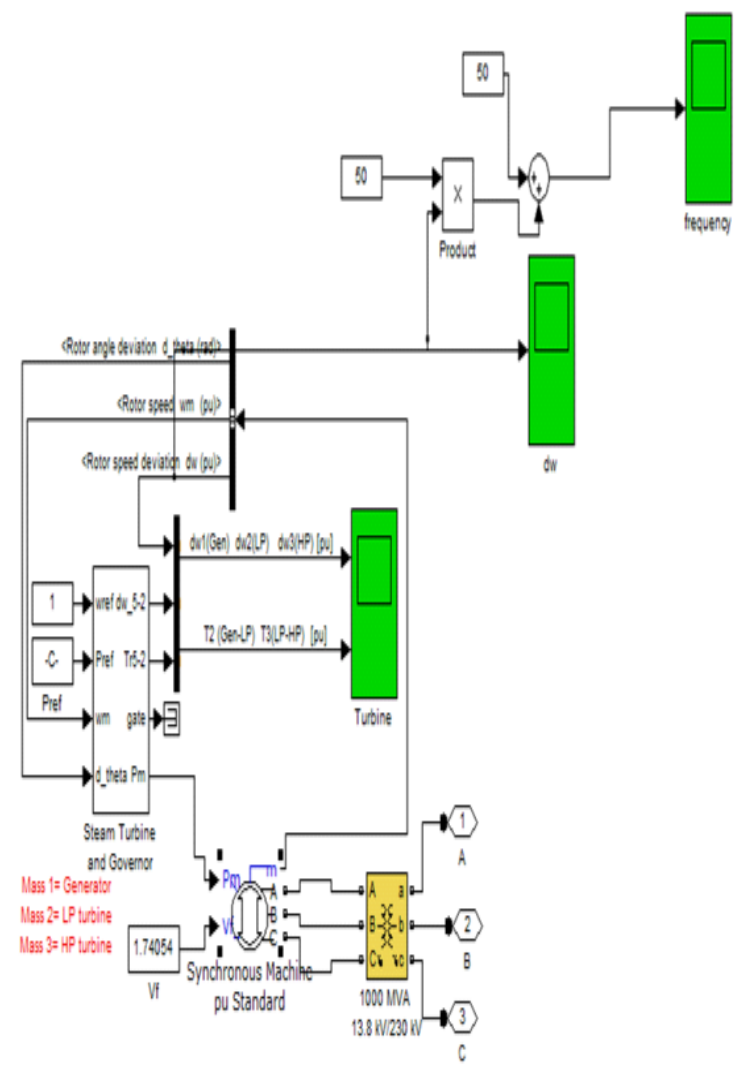

Fig 1 Block Diagram of Synchronous Generator

When loads are increasing or decreasing then frequency will decrease or increase accordingly. For automatic frequency control, ALFC is used in both single and double area loop.

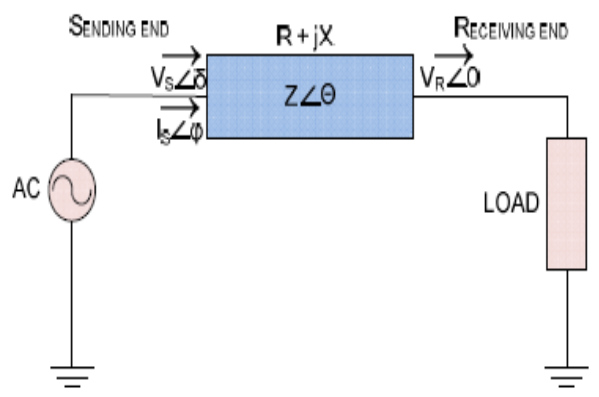

In thermal power plant, frequency can be controlled by automatic frequency control loop (ALFC) which comprises generator, load, prime mover and governor. For a two area system, during normal operation the real power transferred over the tie line is given by

$$
P_{12}=\frac{\left|E_{1}\right|\left|E_{2}\right|}{X_{12}} \sin \delta_{12}
$$

Where $X_{12}=X_{1}+X_{\text {tie }}+X_{2}$
And $\delta_{12}=\delta_{1}-\delta_{2}$

For a small deviation in the tie-line flow

$$
\begin{gathered}
\Delta P_{12}=\left.\frac{d P_{12}}{d \delta_{12}}\right|_{\delta_{12}} \Delta \delta_{12}=P_{s} \Delta \delta_{12} \\
\Delta P_{12}=P_{s}\left(\Delta \delta_{1}-\Delta \delta_{2}\right)
\end{gathered}
$$

The tie-line power deviation then takes on the form

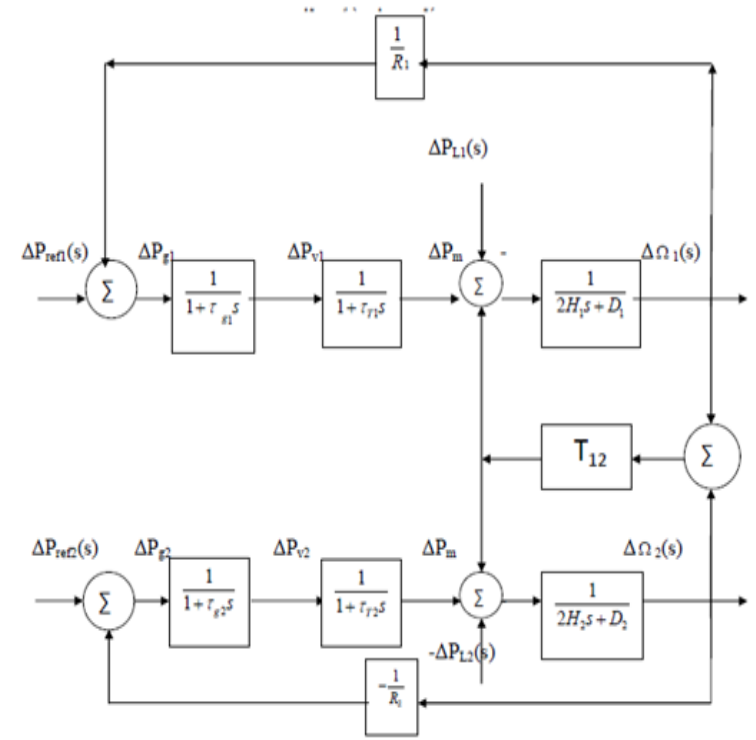

Fig.2 Tie Line Power Representation

\subsection{Frequency Control of DFIG:}

Doubly-fed electric machines are basically electric machines that are fed ac currents into both the stator and the rotor windings. of doubly-fed induction generators when used in wind turbines is that they allow the amplitude and frequency of their output voltages to be maintained at a constant value, no matter the speed of the wind blowing on the wind turbine rotor. Because of this, doubly-fed induction generators can be directly connected to the ac power network and remain synchronized at all times with the ac power network. 


\section{SIMULATION MODEL}

The effects of load variation are studied as follows:

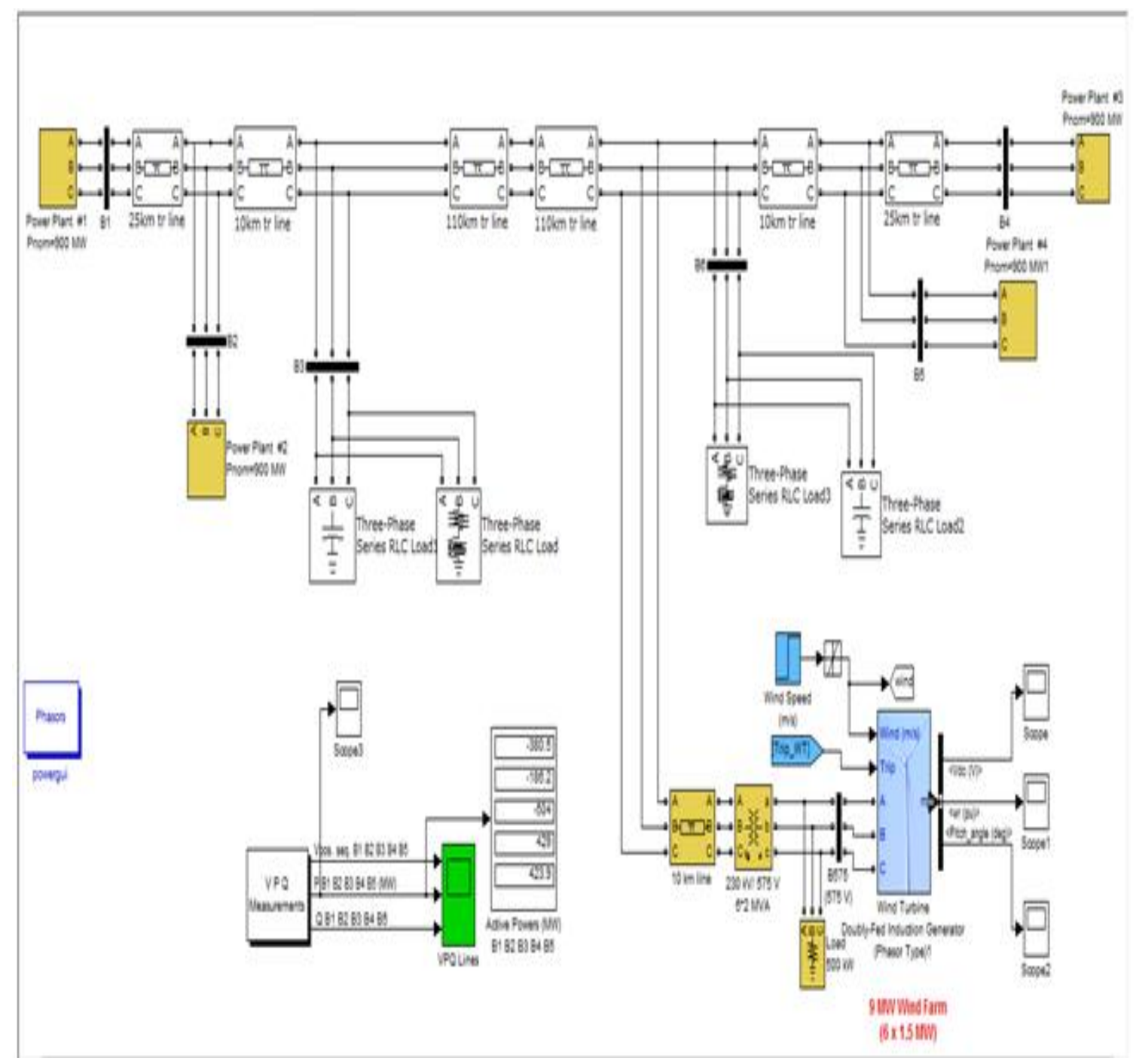

\section{RESULT AND DISCUSSION:}

Initial load values are taken from problem of [11] and simulation has been done. Some of the results are discussed here with their graph data are as:

\subsection{Case I}

\begin{tabular}{|l|l|l|}
\hline \multicolumn{2}{|l|}{ Load at BUS 3} \\
\hline Inductive & Active & Capacitive \\
\hline 150 MVAR & $1100 \mathrm{MW}$ & $200 \mathrm{MVAR}$ \\
\hline Load at BUS 6 & Active & Capacitive \\
\hline Inductive & $1900 \mathrm{MW}$ & 350 MVAR \\
\hline 120 MVAR &
\end{tabular}

The graph of Frequency obtained form this SIMULINK model has shown below:

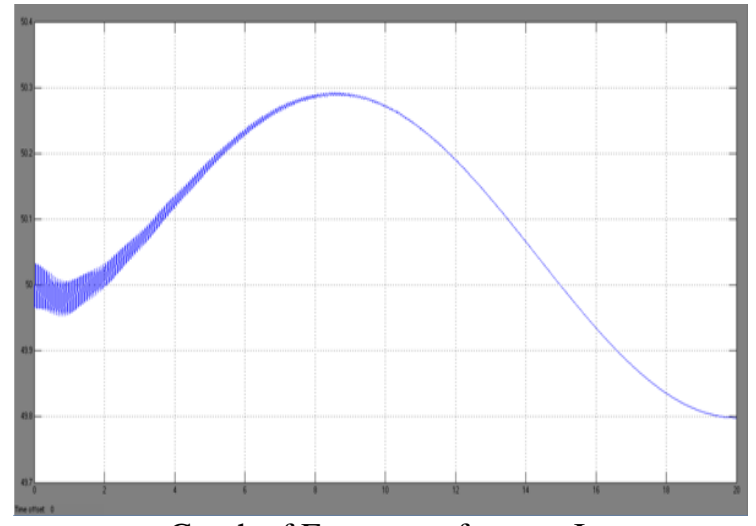

Graph of Frequency for case I

Hence this is observed from above frequency graph that the $\mathrm{f}_{\max }=50.29 \mathrm{~Hz}$ AND $\mathrm{f}_{\min }=49.9 \mathrm{~Hz}$. This is a stable working region of a power system network. 


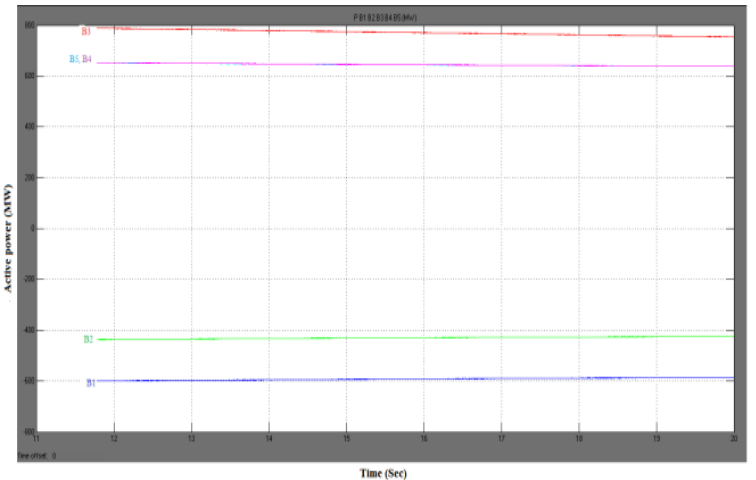

Graph of Active power for case I

The active power values are as: B1-586 MW, B2-424.8 MW, B3-754.1 MW, B4-637.3 MW, B5-638.9 MW

\subsection{Case II}

\begin{tabular}{|l|l|l|}
\hline \multicolumn{4}{|l|}{ Load at BUS 3} \\
\hline Inductive & Active & Capacitive \\
\hline 190 MVAR & $1200 \mathrm{MW}$ & 200 MVAR \\
\hline Load at BUS 6 & \\
\hline Inductive & Active & Capacitive \\
\hline 210 MVAR & $2100 \mathrm{MW}$ & $350 \mathrm{MVAR}$ \\
\hline
\end{tabular}

The graph of Frequency obtained form this SIMULINK model has shown below:

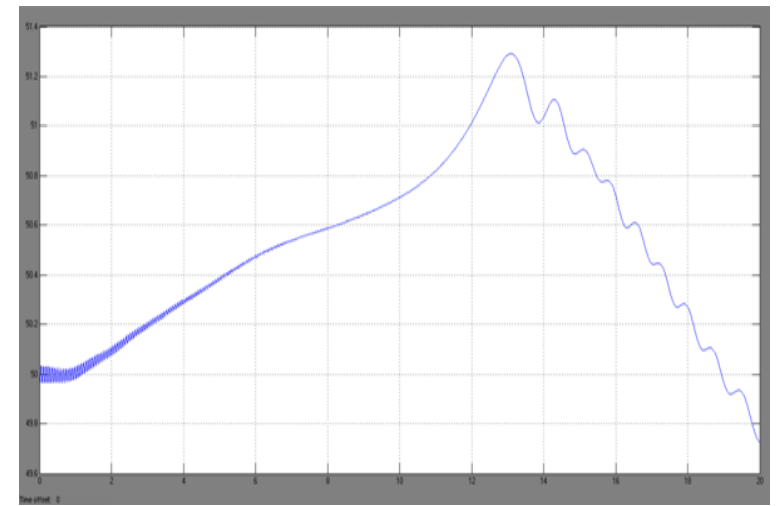

Graph of Frequency for case II

Hence this is observed from above frequency graph that the $\mathrm{f}_{\max }=50.06 \mathrm{~Hz}$ AND $\mathrm{f}_{\min }=49.81 \mathrm{~Hz}$. This is a stable working region of a power system network.

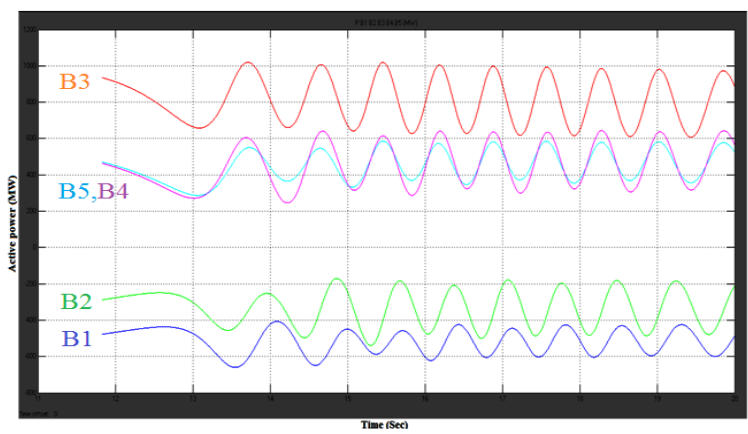

Graph of active powers for case II
The active power values at different buses are:

B1- 628.4 MW, B2- 466.6 MW, B3- 824.7MW ,B4680.7MW ,B5- 680.1 MW

\subsection{Case III}

\begin{tabular}{l|l|l|}
\hline \multicolumn{2}{|l|}{ Load at BUS 3} \\
\hline Inductive & Active & Capacitive \\
\hline 100 MVAR & $960 \mathrm{MW}$ & 200 MVAR \\
\hline Load at BUS 6 & Active & Capacitive \\
\hline Inductive & $1760 \mathrm{MW}$ & $350 \mathrm{MVAR}$ \\
\hline 100 MVAR & &
\end{tabular}

The graph of Frequency obtained form this SIMULINK model has shown below:

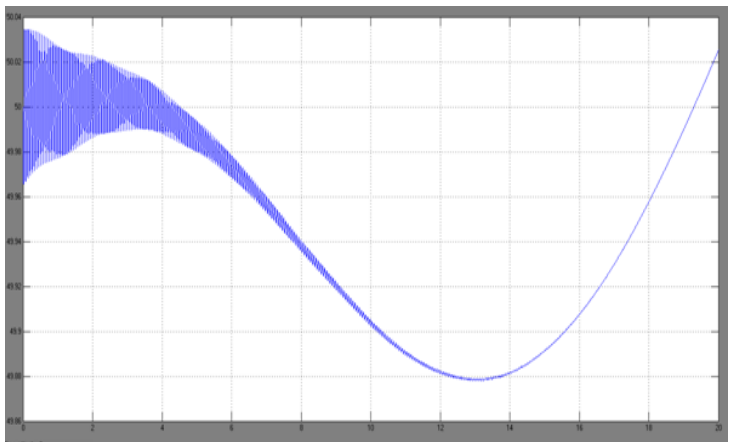

Graph of Frequency for case III

Hence this is observed from above frequency graph that the $\mathrm{f}_{\max }=51.23 \mathrm{~Hz}$ AND $\mathrm{f}_{\min }=49.78 \mathrm{~Hz}$. This is a stable working region of a power system network

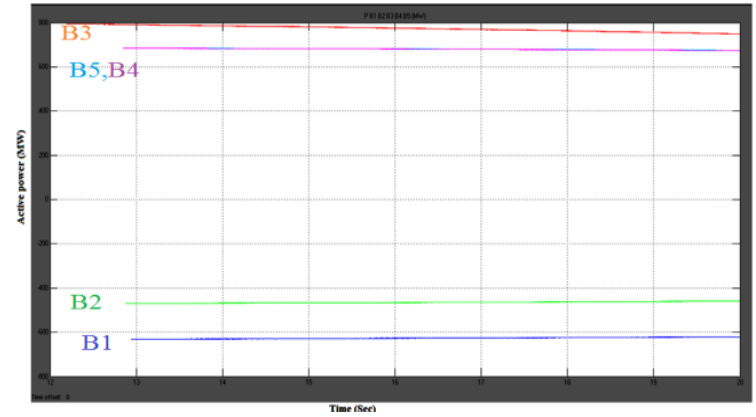

Graph of active powers for case III

The active power values are:

B1- 489.7 MW ,B2- 213.2 MW ,B3- 887.9 MW , B4- 527.1 MW ,B5- 568.1 MW

\subsection{Case IV}

\begin{tabular}{|c|c|c|}
\hline \multicolumn{3}{|c|}{ Load at BUS 3} \\
\hline Inductive & Active & Capacitive \\
\hline 50 MVAR & $650 \mathrm{MW}$ & $200 \mathrm{MVAR}$ \\
\hline \multicolumn{3}{|c|}{ Load at BUS 6} \\
\hline Inductive & Active & Capacitive \\
\hline 40 MVAR & $1400 \mathrm{MW}$ & $350 \mathrm{MVAR}$ \\
\hline
\end{tabular}


The graph of Frequency obtained from this SIMULINK model is shown below:

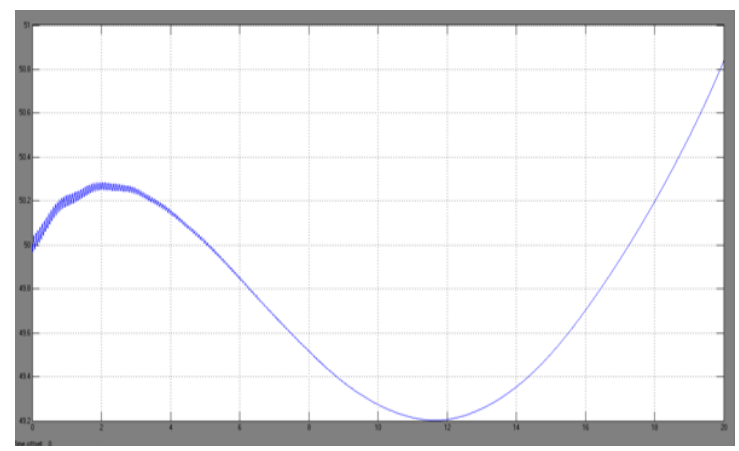

Graph of Frequency for case IV

Hence this is observed from above frequency graph that the $\mathrm{f}_{\max }=50.80 \mathrm{~Hz}$ AND $\mathrm{f}_{\min }=49.2 \mathrm{~Hz}$. This is a stable working region of a power system network.

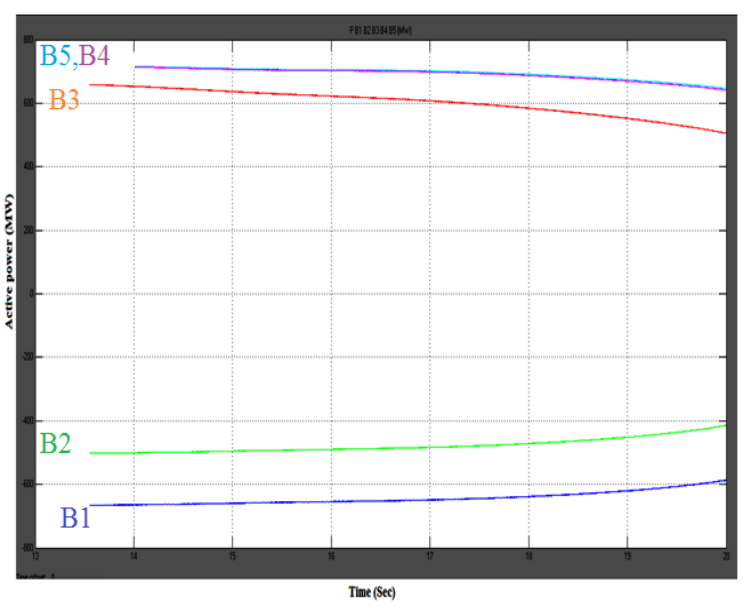

Graph of active powers for case IV

The active power values are:

B1-586.9 MW, B2- 414.4 MW, B3- 505.6 MW, B4- 646.8 MW, B5- 641.9 MW

In load analysis of above simulation model, Inductive and Active loads are varied in RL series load which is taken at both load buses i.e. B3 and B6. Whereas capacitive load kept as it is with the initial value taken in series load. The value of capacitive load at bus bar B3 is 200 MVAR where as 350 MVAR of capacitive value is taken at bus bar B6. Initially active and inductive load at B3 is taken as $1100 \mathrm{MW}$ and 150 MVAR respectively and at B6 the value of active load is 1900 MW and the value of inductive load is 120 MVAR. The maximum and minimum measured frequency values on these loads are $50.29 \mathrm{~Hz}$ and $49.90 \mathrm{~Hz}$ respectively. The positive frequency deviation is calculated to $0.20 \%$ and the calculated value of negative frequency deviation is $0.584 \%$. Since both the positive and negative frequency deviation result comes under the defined stable frequency deviation range which is $\pm 3 \%$. This result shows that this smart grid power system is stable on these load values. Respective active power values also has been noted down and values at different bus bars are : B1-586 MW, B2424.8 MW, B3-754.1 MW, B4-637.3 MW, B5-638.9 MW
Inductive and Active loads at both buses has increased simultaneously and this is found that when inductive and active load values at bus B3 is 190 MVAR and 1200MW and load value at bus B6 is 210 MVAR and $2100 \mathrm{MW}$ then active power measured at all buses namely B1, B2, B3, B4 and B5 are not constant throughout the process and it is varying time to time which is an undesirable result for a stable power system network. Although frequencies measured are within the stable range. Minimum and maximum frequencies measured at these load values are $49.81 \mathrm{~Hz}$ and $50.06 \mathrm{~Hz}$ respectively. The positive frequency deviation is $0.12 \%$ and $0.38 \%$ which is within $\pm 3 \%$.

The maximum values of load has already taken to check the maximum limit of this smart grid network and it has seen that at that maximum values of load, frequency is under stable range but nature of active power is no more compatible for applied load to their corresponding buses. So in another case, magnitude of both active and inductive loads has decreased on both load buses to know the range of loads that can be attached to the power system network for a stable operation. To know these load ranges, value of inductive load on bus bar B3 is decreased to 50MVAR from their initial value which is $150 \mathrm{MVAR}$ and value of active load is decreased to $650 \mathrm{MW}$ from their initial value of $1100 \mathrm{MW}$ where as at bus bar B6, inductive load is decreased from 120MVAR to 40MVAR and active load is decreased from 1900MW to 1400MW. At these lowest load values, the values of maximum and minimum frequencies are measured to $50.80 \mathrm{~Hz}$ and $49.20 \mathrm{~Hz}$. The positive and negative frequency deviation is calculated to the same value of $1.60 \%$. Although this frequency deviation comes under the defined frequency deviation range i.e. $\pm 3 \%$ but it is seen that the worst power blackout had happened on July '2013 in India occurred on $49.20 \mathrm{~Hz}$ only. So to take the standard of $49.20 \mathrm{~Hz}$, the load is varied to get the frequency value of $49.20 \mathrm{~Hz}$. So final range of inductive load on bus bar B3 is from $190 \mathrm{MVAR}$ to $50 \mathrm{MVAR}$ and final range of active load is from $1200 \mathrm{MW}$ to $650 \mathrm{MW}$ where as maximum variation of inductive load on bus bar B6 is from 210 MVAR to $40 \mathrm{MVAR}$ and for active load the range is from $2100 \mathrm{MW}$ to $1400 \mathrm{MW}$.

\section{CONCLUSIONS}

In this paper, load analysis is done on this smart grid to check the stability in terms of frequency deviation. Since the standard frequency deviation is defined in $\pm 3 \%$ range. Initial value of inductive and active load is taken as 150 MVAR and $1100 \mathrm{MW}$ at load bus bar B3 and 120 MVAR and 1900 MW at B6 respectively. At these load values maximum and minimum frequencies obtained as $50.292 \mathrm{~Hz}$ and $49.90 \mathrm{~Hz}$ respectively. From these frequency value positive and negative frequency deviation is calculated as $0.20 \%$ and $0.584 \%$ respectively which comes under defined frequency deviation range increasing the load values. The different values of active power at different buses shows that proposed design of smart grid model is sufficient to sustain the inductive and active load variation. 


\section{REFERENCES}

[1] Xi Fang, Student Member, IEEE,SatyajayantMisra, Member, IEEE, GuoliangXue, Fellow, IEEE, and Dejun Yang, Student Member, IEEE, "Smart Grid The New and Improved Power Grid: A Survey", IEEE Trans. Smart Grid, 2011

[2] F. Rahimi, A. Ipakchi, "Demand response as a market resource under the smart grid paradigm". IEEE Trans. Smart Grid, 1(1):82-88, 2010.

[3] P. B. Andersen, B. Poulsen, M. Decker, C. Træholt, and J. Østergaard. "Evaluation of a generic virtual power plant framework using service oriented architecture". IEEE PECon'08, pages 1212-1217, 2008.

[4] P. B. Andersen, B. Poulsen, M. Decker, C. Træholt, and J. Østergaard. "Evaluation of a generic virtual power plant framework using service oriented architecture". IEEE PECon'08, pages 1212-1217, 2008

[5] C. Marinescu and S. I, "Analysis of frequency stability in a residential autonomous microgrid based on the wind turbine and microhydel power plant," Optimization of electrical and electronic equipment, vol. 50, pp. 1186-1191, 2010

[6] P.Piagi, "Microgrid control," Ph.D. dissertation, Electrical enginnering department, University of Wisconsin -Madisson, August 2005.

[7] P.Piagi and R. Lasseter, "Autonomous control of microgrids," 2006.

[8] G.Lalor, "Frequency control on an isolated power system with evolving plant mix," Ph.D. dissertation, School of electrical and mechanical Engineering, University College Dublin, September 2005.

[9] H.A. Khan, H.C. Iu, V. Sreeram, "Active and Reactive power control of the Electronically interfaced DG sources for the Realization of a virtual power plant"

[10] R. Doherty, etal, "System operation with a significant wind power penetration," IEEE PowerEngineering Society General Meeting, Vol.1, pp. 1002-1007, 2004.

[11] P Kundur, "Power system stability and control “ 